\title{
Synthesis of $\mathrm{NaYF4:Yb/Er/Gd} \mathrm{up-conversion} \mathrm{luminescent}$ nanoparticles and luminescence resonance energy transfer- based protein detection
}

\author{
Jingpu Zhang ${ }^{\mathrm{a}}$, Congcong $\mathrm{Mi}^{\mathrm{a}}$, Hongyan $\mathrm{Wu}^{\mathrm{a}}$, Huaiqing Huang ${ }^{\mathrm{a}}$, Chuanbin Mao ${ }^{\mathrm{b},{ }^{*}}$, and \\ Shukun $\mathrm{Xu}^{\mathrm{a}}$, \\ aDepartment of Chemistry, Northeastern University, Shenyang 110819, People's Republic of \\ China \\ ${ }^{b}$ Department of Chemistry and Biochemistry, Stephenson Life Sciences Research Center, \\ University of Oklahoma, Norman, OK 73019, USA
}

\section{Abstract}

High-quality $\mathrm{NaYF}_{4}: \mathrm{Yb} / \mathrm{Er} / \mathrm{Gd}$ up-conversion nanoparticles (UCNPs) were first synthesized by a solvothermal method using rare earth stearate, sodium fluoride, ethanol, water, and oleic acid as precursors. Doped $\mathrm{Gd}^{3+}$ ions can promote the transition of $\mathrm{NaYF}_{4}$ from cubic to hexagonal phase, shorten the reaction time, and reduce the reaction temperature without reducing the luminescence intensity of $\mathrm{NaYF}_{4}: \mathrm{Yb} / \mathrm{Er}$ UCNPs. X-ray diffraction, infrared spectroscopy, transmission electron microscopy, and luminescence spectroscopy were applied to characterize the UCNPs. The nanoparticles exhibited small size and excellent green up-conversion photoluminescence, making them suitable for biological applications. After the surfaces of $\mathrm{NaYF}_{4}: \mathrm{Yb} / \mathrm{Er} / \mathrm{Gd} \mathrm{UCNPs}$ were modified with amino groups through the Stöber method, they could be brought close enough to the analytically important protein called R-phycoerythrin (R-PE) bearing multiple carboxyl groups so that energy transfer could occur. A luminescence resonance energy transfer (LRET) system was developed using $\mathrm{NaYF}_{4}: \mathrm{Yb} / \mathrm{Er} / \mathrm{Gd} \mathrm{UCNPs}$ as an energy donor and R-PE as an energy acceptor. As a result, a detection limit of R-PE of $0.5 \mu \mathrm{g} / \mathrm{ml}$ was achieved by the LRET system with a relative standard deviation of $2.0 \%$. Although this approach was first used successfully to detect R-PE, it can also be extended to the detection of other biological molecules.

\section{Keywords}

$\mathrm{NaYF}_{4}: \mathrm{Yb} / \mathrm{Er} / \mathrm{Gd}$ nanoparticles; Up-conversion luminescence; Stöber method; Luminescence resonance energy transfer; Phycoerythrin

Up-conversion (UC) ${ }^{1}$ is an anti-Stokes process where a longer wavelength radiation, usually near-infrared (NIR) or infrared (IR), is converted to a shorter wavelength such as ultraviolet (UV) or visible (Vis) radiation via a two-photon or multiphoton mechanism [1,2]. In

\footnotetext{
(C) 2011 Elsevier Inc. All rights reserved.

*Corresponding authors. Fax: +1 4053256111 (C. Mao), +86 2483687673 (S. Xu). cbmao@ou.edu (C. Mao), xushukun46@126.com (S. Xu).

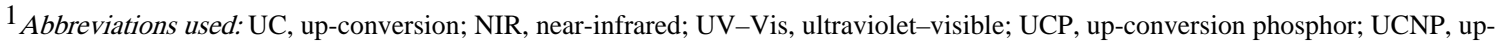
conversion nanoparticle; RE, rare earth; PVP, polyvinylpyrrolidone; R-PE, R-phycoerythrin; FRET, Förster resonance energy transfer; LRET, luminescence resonance energy transfer; DL, detection limit; RSD, relative standard deviation; NaF, sodium fluoride; TEOS, tetraethyl orthosilicate; APTES, 3-aminopropyltrimethoxysilane; EDC, $N$-ethyl- $N^{\prime}$-[3-(dimethylamino)propyl]carbodiimide hydrochloride; TEM, transmission electron microscope; XRD, X-ray diffraction; FT-IR, Fourier transform infrared; PBS, phosphate buffer solution; EDS, energy dispersive spectroscopy.
} 
addition to applications in laser materials, NIR quantum counters, lighting and display technologies [3-9], there is a growing interest in the application of nano-sized up-conversion phosphors (UCPs) as fluorescent labels for sensitive biological detection [10-12]. When UCPs are used as biolabels, NIR radiation is used to excite UCPs. As a result, very weak autofluorescence can be detected from sample matrix; accordingly, very low background fluorescence from the biological samples can interfere with the specific signal [13]. Therefore, a high signal/noise ratio $(\mathrm{S} / \mathrm{N})$ will be obtained.

It has been well accepted that $\mathrm{NaYF}_{4}: \mathrm{Yb}$,Er up-conversion nanoparticles (UCNPs) have the best luminescence property among UC fluorescent materials [14-16]. Several methods for the preparation of $\mathrm{NaYF}_{4}: \mathrm{Yb}$,Er UCNPs have been reported, including the coprecipitation method, the thermal decomposition method, and the hydrothermal/solvothermal method [17-21]. The coprecipitation method was one of the easiest and most convenient approaches, but the UCNPs tended to aggregate into larger sizes. The thermal decomposition method was a good route for synthesizing high-quality rare earth (RE)-doped $\mathrm{NaYF}_{4}$ UCNPs, but it requires harsh conditions. The hydrothermal/solvothermal method can be used to improve the water solubility and biocompatibility of the UCNPs. During recent years, this method has been used rather widely for preparing $\mathrm{NaYF}_{4}: \mathrm{Yb}, \mathrm{Er} \mathrm{UCNPs}$. The disadvantage of this method is the long reaction time required to achieve desired UCNPs' morphology; indeed, when the reaction time is $7 \mathrm{~h}$ or less, cubic $\mathrm{NaYF}_{4}$ UCNPs are the main product rather than hexagonal $\mathrm{NaYF}_{4} \mathrm{UCNPs}$.

UC luminescent nanocrystals can convert an NIR excitation into a visible emission through lanthanide doping [22]. Haase's group developed a method for preparing colloid lanthanidedoped $\mathrm{NaYF}_{4}$ nanocrystals that were transparently soluble in nonpolar solvent [23]. Zhang and coworkers reported a method for the synthesis of water-soluble and biocompatible polyethylenimine-coated $\mathrm{NaYF}_{4}$ nanoparticles doped with lanthanide ions [24] as well as biocompatible silica-coated $\mathrm{NaYF}_{4} \mathrm{UC}$ fluorescent nanocrystals [25]. Unfortunately, these nanoparticles cannot be used directly in biological applications because of the presence of some hydrophobic organic ligands as well as the absence of appropriate functional groups on the surface of the nanoparticles. A good example of coating the surface with silica was reported by Li and Zhang [26], who coated polyvinylpyrrolidone (PVP)-stabilized $\mathrm{NaYF}_{4}: \mathrm{Yb}, \mathrm{Er} / \mathrm{Tm} \mathrm{UCNPs}$ with a layer of silica via the typical Stöber method.

R-phycoerythrin (R-PE) [27] is a red protein that can serve as an indicator of the presence of cyanobacteria and as a probe for labeling antibodies. R-PE possesses several unique characteristics, such as nontoxicity, strong fluorescence, and small background light interference, making it an attractive candidate for fluorescence labeling in the analysis of biomolecules and cells. It also has potential applications in the polychromatic fluorescence immune detection of animal epidemic mixed infection, bird flu, and other animal epidemics. Therefore, it is important to develop a method for the detection of R-PE.

Förster resonance energy transfer (FRET) is a nonradiative process in which the electronic excitation energy of a donor chromophore is transferred to a nearby acceptor molecule via long-range dipole-dipole interactions [28] and has been widely used for immunoassay [29]. In this work, UCNPs doped with $\mathrm{Gd}^{3+}$ ions were synthesized by a solvothermal method and used for luminescence resonance energy transfer (LRET)-based detection of R-PE. The excellent $\mathrm{NaYF}_{4}: \mathrm{Yb} / \mathrm{Er} / \mathrm{Gd} \mathrm{UCNPs}$ were synthesized with shorter time and lower temperature through doping of $\mathrm{Gd}^{3+}$ ions, which could promote the transition of $\mathrm{NaYF}_{4}$ from cubic to hexagonal. Then, the $\mathrm{NaYF}_{4}: \mathrm{Yb} / \mathrm{Er} / \mathrm{Gd} \mathrm{UCNPs}$ were modified by the typical Stöber method and used as an energy donor to develop an LRET system for detection of R-

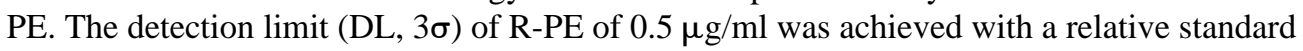


deviation (RSD) of $2.0(21.9 \mu \mathrm{g} / \mathrm{ml}, n=11)$, and this method is expected to be expanded to the detection of other proteins.

\section{Materials and methods}

\section{Materials}

All chemical reagents used in the experiment, specifically rare earth oxide $\left(\mathrm{RE}_{2} \mathrm{O}_{3}\right)$, sodium fluoride $(\mathrm{NaF})$, oleic acid $\left(\mathrm{C}_{17} \mathrm{H}_{33} \mathrm{COOH}\right)$, stearic acid $\left(\mathrm{C}_{17} \mathrm{H}_{35} \mathrm{COOH}\right)$, disodium hydrogen phosphate dodecahydrate $\left(\mathrm{Na}_{2} \mathrm{HPO}_{4} \cdot 12 \mathrm{H}_{2} \mathrm{O}\right)$, sodium dihydrogen phosphate dehydrate $\left(\mathrm{NaH}_{2} \mathrm{PO}_{4} \cdot 2 \mathrm{H}_{2} \mathrm{O}\right)$, tetraethyl orthosilicate (TEOS), and 3-aminopropyltrimethoxysilane (APTES), were of analytical grade and did not undergo any further purification (purchased from National Medicines Corporation, China). $N$-ethyl- $N^{\prime}$-[3-(dimethylamino)propyl]carbodiimide hydrochloride (EDC) was obtained from Acros (USA). R-PE was obtained from H\&R Bioscience (China). Triple-distilled water was used throughout the experiments.

\section{Synthesis and modification of RE-doped $\mathrm{NaYF}_{4}$ UCNPs}

$\mathrm{NaYF}_{4}: \mathrm{Yb} / \mathrm{Er} / \mathrm{Gd} \mathrm{UCNPs}$ were synthesized according to a previously reported procedure [21] in which rare earth stearate $\left[\left(\mathrm{C}_{17} \mathrm{H}_{35} \mathrm{COOH}\right)_{3} \mathrm{RE}\right]$ was used as the precursor and oleic acid was used as the stabilizing agent. At first, RE stearate $(1 \mathrm{~mol}), \mathrm{NaF}(0.2011 \mathrm{~g})$, ethanol $(15 \mathrm{ml})$, water $(10 \mathrm{ml})$, and oleic acid $(4 \mathrm{ml})$ were mixed together and stirred to form a homogeneous solution. Then, the mixed solution was treated at $150{ }^{\circ} \mathrm{C}$ for $7 \mathrm{~h}$ with a highpressure nitrifying pot. After reaction, the product was separated by centrifugation at 8500 rpm and then dried at $60{ }^{\circ} \mathrm{C}$ for $10 \mathrm{~h}$. A series of $\mathrm{NaYF}_{4}: \mathrm{Yb} / \mathrm{Er} / \mathrm{Gd}_{X} \mathrm{UCNPs}$ were obtained by tuning the amount of $\left(\mathrm{C}_{17} \mathrm{H}_{35} \mathrm{COOH}\right)_{3} \mathrm{Gd}$.

Surface modification of $\mathrm{NaYF}_{4}$ UCNPs was completed using the typical Stöber-based method reported in our previous work [14]. Briefly, $20 \mathrm{mg}$ of $\mathrm{NaYF}_{4} \mathrm{UCNPs}_{\text {was }}$ dispersed in isopropyl alcohol $(70 \mathrm{ml})$ and treated by ultrasonication at room temperature for $40 \mathrm{~min}$. Then, $2.5 \mathrm{ml}$ of $15 \% \mathrm{NH}_{3} \cdot \mathrm{H}_{2} \mathrm{O}$ and $10 \mathrm{ml}$ of triple-distilled water were added to the mixture, followed by the dropwise addition of TEOS $(20 \mu \mathrm{l})$ and APTES $(200 \mu \mathrm{l})$. After the reaction reached completion, the product was washed with ethanol, centrifuged, and finally dried at $60{ }^{\circ} \mathrm{C}$.

\section{Characterization}

The size and morphology of as-prepared nanoparticles were observed on a JEM-2100HR transmission electron microscope (TEM, JEOL, Japan) using an accelerating voltage of 200 $\mathrm{kV}$. X-ray diffraction (XRD) measurements were performed on a D/max 2500/PC diffractometer (JEOL) at a scanning rate of $8 \% \mathrm{~min}$ with graphite monochromatized $\mathrm{Cu} \mathrm{Ka}$ radiation $(\lambda=0.15406 \mathrm{~nm})$. UC luminescence spectra of the dried and powdered nanoparticles were measured on an LS-55 fluorescence spectrophotometer (PerkinElmer, USA) attached to an external 980-nm laser (Beijing Hi-Tech Opto-electronics, China) instead of the internal excitation source. The maximum power of the laser was $1200 \mathrm{~mW}$. Fourier transform infrared (FT-IR) spectra of the silica-coated UCNPs were measured on a Spectrum One (B) spectrometer (PerkinElmer) by using the KBr method.

\section{Pretreatment of R-PE}

The R-PE solution obtained from H \& R Bioscience was treated by centrifugation at 3000 $\mathrm{rpm}$ at $4{ }^{\circ} \mathrm{C}$. After the supernatant was completely removed, the deposit was dissolved in phosphate buffer solution (PBS, pH 7.0). Then, the mixture was dialyzed with dialysis tubing for $10 \mathrm{~h}$ under constant stirring. Finally, it was separated by centrifugation, where the 
deposit was removed and the supernatant was reserved for the UV-Vis absorption and fluorescence spectrometric detection.

\section{Preparation of P-RE/NaYF 4 :Yb,Er,Gd LRET systems}

Here, $0.8 \mathrm{mg}$ of amino-modified $\mathrm{NaYF}_{4}: \mathrm{Yb} / \mathrm{Er} / \mathrm{Gd}$ UCNPs was dispersed in $1 \mathrm{ml}$ of PBS (pH 7.0) by ultrasonication for $30 \mathrm{~min}$. Then, $1 \mathrm{ml}$ of $0.8 \mathrm{mg} / \mathrm{ml} \mathrm{NaYF} / \mathrm{NH}_{2}$ and $0.2 \mathrm{ml}$ of $0.2 \mathrm{mg} / \mathrm{ml} \mathrm{EDC}$ were added into a series of tubes containing different volumes $(0.002-0.13$ $\mathrm{ml}$ ) of $0.875 \mathrm{mg} / \mathrm{ml} \mathrm{R}-\mathrm{PE}$. The final solution volume was then adjusted to $2 \mathrm{ml}$ with PBS. This series of solutions was incubated for $15 \mathrm{~min}$ with low shaking at room temperature. After that, the solutions were reactivated for $2 \mathrm{~h}$ at $4{ }^{\circ} \mathrm{C}$. The visible light emission of the resultant system can be detected by $980 \mathrm{~nm}$ excitation.

\section{Results and discussion \\ Influence of doped RE $\mathrm{Gd}^{3+}$ ions}

Fig. 1A shows the UC luminescence intensity of the $\mathrm{NaYF}_{4}: \mathrm{Yb} / \mathrm{Er} / \mathrm{Gd}$ UCNPs with different reaction times and amounts of doped $\mathrm{RE} \mathrm{Gd}^{3+}$. It can be seen that with increasing reaction time, the luminescence intensity of the $\mathrm{NaYF}_{4}: \mathrm{Yb} / \mathrm{Er} / \mathrm{Gd}$ UCNPs became much stronger for reaction time shorter than $10 \mathrm{~h}$. When the reaction time was invariant, the luminescence intensity of the UCNPs first increased and then decreased along with the increasing molar ratio of the doped $\mathrm{RE} \mathrm{Gd}^{3+}$ ions, but all of them were better than the case without doping $\mathrm{Gd}^{3+}$ ions. By increasing reaction time and gradually decreasing the molar ratio of the doped $\mathrm{RE} \mathrm{Gd}^{3+}$ from $7 \%$ to $3 \%$, the luminescence intensity reached a maximum. Because the reaction was more complete as the reaction time increased, the luminescence intensity of the $\mathrm{NaYF}_{4}: \mathrm{Yb} / \mathrm{Er} / \mathrm{Gd}$ UCNPs became more sensitive to the doped RE Gd ${ }^{3+}$. Meanwhile, it can be seen in Fig. 1B that from $\mathrm{NaYF}_{4}: \mathrm{Yb} / \mathrm{Er}(20 / 2 \mathrm{~mol} \%)$ to $\mathrm{NaYF}_{4}: \mathrm{Yb} / \mathrm{Er} /$ Gd (20/2/3 mol\%), the luminescence intensity of the UCNPs changes over different reaction times $(4,6,7,8$, and $10 \mathrm{~h})$. These results show that the maximum luminescence intensity change was obtained with the reaction time of $7 \mathrm{~h}$.

From Fig. 1, it can also be seen that in a short reaction time ( $<10 \mathrm{~h})$, the luminescence intensity of $\mathrm{NaYF}_{4}: \mathrm{Yb} / \mathrm{Er} / \mathrm{Gd}_{X}(x=0-15 \mathrm{~mol} \%)$ UCNPs is stronger than that of $\mathrm{NaYF}_{4}: \mathrm{Yb} /$ Er UCNPs under the same reaction conditions. The intensity of the $\mathrm{NaYF}_{4}: \mathrm{Yb} / \mathrm{Er} / \mathrm{Gd}_{X}(x=3$ mol\%) with the reaction time of $7 \mathrm{~h}$ is roughly the same as that of the $\mathrm{NaYF}_{4}: \mathrm{Yb} / \mathrm{Er}$ UCNPs with the reaction time of $10 \mathrm{~h}$. Namely, we can get the same intensity with reduced reaction time by doping $\mathrm{Gd}^{3+}$ ions.

The XRD patterns of the prepared nanoparticles with and without $\mathrm{Gd}^{3+}$ doping are shown in Fig. 2. All of the samples were prepared for $7 \mathrm{~h}$ at $150^{\circ} \mathrm{C}$. It can be seen that, without $\mathrm{Gd}^{3+}$ ions, the $\mathrm{NaYF}_{4}: \mathrm{Yb} / \mathrm{Er}(20 / 2 \mathrm{~mol} \%)$ UCNPs are mainly the cubic phase of $\mathrm{NaYF}_{4}$ (JCPDS no. 77-2042), whereas those doped with $3 \mathrm{~mol} \%$ of $\mathrm{Gd}^{3+}$ are mainly the hexagonal phase of $\mathrm{NaYF}_{4}$ (JCPDS no. 28-1192). Namely, there is an evident transformation from cubic to hexagonal due to the doping. When the $\mathrm{Gd}^{3+}$ concentration is further increased to $15 \mathrm{~mol} \%$, the cubic phase of $\mathrm{NaYF}_{4}$ does not change significantly because of the formation of cubic phase of $\mathrm{NaGdF}_{4}$, whereas the luminescence intensity declines somewhat. It can be concluded that the cubic-to-hexagonal phase conversion is promoted only at the proper level of doped $\mathrm{Gd}^{3+}$. When the products were prepared without doped $\mathrm{Gd}^{3+}$, the structure of UCNPs was mainly the cubic phase of $\mathrm{NaYF}_{4}$, which is unable to emit UC luminescence and, thus, cannot be used for biological applications. After being doped with a small amount of the $\mathrm{Gd}^{3+}(3 \mathrm{~mol} \%)$, the structure of UCNPs is mainly the hexagonal $\mathrm{NaYF}_{4}$, which can be used in biological application. With further increased $\mathrm{Gd}^{3+}$ ion concentration, the cubic-tohexagonal phase transformation process is not further improved due to the formation of the $\mathrm{NaGdF}_{4}$. 
TEM was used to observe the morphology and size of the $\mathrm{Yb} / \mathrm{Er}$ and $\mathrm{Yb} / \mathrm{Er} / \mathrm{Gd}$-doped nanoparticles. As shown in Fig. 3, there is no obvious difference in the shape and size of nanoparticles between $\mathrm{NaYF}_{4}: \mathrm{Yb} / \mathrm{Er}$ and $\mathrm{NaYF}_{4}: \mathrm{Yb} / \mathrm{Er} / \mathrm{Gd}_{X}(x=3 \mathrm{~mol} \%)$. The $\mathrm{Gd}^{3+}$-doped UCNPs have an average size of $30 \mathrm{~nm}$ and are spherical in shape. Those doped with $\mathrm{Gd}^{3+}$ concentrations up to $15 \mathrm{~mol} \%$ have a primarily rod-like shape rather than spherical shape due to the formation of $\mathrm{NaGdF}_{4}$. This result is in agreement with the XRD results (Fig. 2).

It is well known that $\mathrm{NaYF}_{4}: \mathrm{Yb} / \mathrm{Er}$ UCNPs synthesized by the solvothermal method, which needs longer reaction time, show well-established, efficient UC luminescence and are suited for biological application. When the reaction time is shorter than $7 \mathrm{~h}$, the products are cubic $\mathrm{NaYF}_{4}$ crystal, which cannot emit UC luminescence and cannot be used in biolabeling applications. After the addition of a suitable amount of $\mathrm{RE} \mathrm{Gd}^{3+}$, the transformation from cubic to hexagonal structure of $\mathrm{NaYF}_{4}$ in these samples occurred, leading to the production of UCNPs mainly in the hexagonal structure of $\mathrm{NaYF}_{4}$. This result can be attributed to the small structural difference between the hexagonal phase $\mathrm{NaYF}_{4}$ and $\mathrm{NaGdF}_{4}$. It can be seen that the peak shifts toward lower diffraction angles because $\mathrm{Y}^{3+}$ ions were replaced by the larger $\mathrm{Gd}^{3+}$ ions in the host lattice from Fig. 2 [30]. By further increasing the concentration of $\mathrm{Gd}^{3+}$ ions, the crystal phase changed back to cubic and the nano-particles took a rod-like shape due to the formation of the cubic phase of $\mathrm{NaGdF}_{4}$ instead of the cubic phase of $\mathrm{NaYF}_{4}$. It can be seen that through doping with a suitable amount of $\mathrm{Gd}^{3+}$, the reaction temperature can be lower $\left(150^{\circ} \mathrm{C}\right)$ and the reaction time can be reduced to $7 \mathrm{~h}$ while keeping the luminescence intensity strong enough to be used in biological applications. As an additional benefit, the use of paramagnetic $\mathrm{Gd}^{3+}$ dopant ions may be able to provide the nanocrystals with a second functionality, namely a magnetic capability for magnetic resonance imaging probes [31].

Fluorescent spectra, XRD, and TEM results show that doping a suitable amount of $\mathrm{Gd}^{3+}$ ions can promote the phase transition of the $\mathrm{NaYF}_{4}$ UCNPs from cubic to hexagonal, whereas the shape and size of the nanoparticles are almost unchanged. It is well known that hexagonal-phase ( $\beta$-phase) $\mathrm{NaYF}_{4}$ is a more efficient UC host material than the cubic phase under $980 \mathrm{~nm}$ excitation [14]. As a result, after being doped with $\mathrm{Gd}^{3+}$ ions, UC luminescent intensity of the $\mathrm{NaYF}_{4}$ UCNPs was largely enhanced due to the formation of hexagonal phase.

\section{Surface features of $\mathrm{NaYF}_{4}: \mathrm{Yb} / \mathrm{Er} / \mathrm{Gd}$ nanoparticles before and after surface modification}

Fig. 3D shows the TEM image of $\mathrm{NaYF}_{4}: \mathrm{Yb} / \mathrm{Er} / \mathrm{Gd}(20 / 2 / 3 \mathrm{~mol} \%)$ UCNPs prepared in $7 \mathrm{~h}$ at $150{ }^{\circ} \mathrm{C}$. It shows that the UCNPs are spherical in shape and fairly uniform, but some UCNPs tend to be rod-like because of the doped $\mathrm{Gd}^{3+}$. It can be seen that the average size of the UCNPs is roughly $30 \mathrm{~nm}$, which can meet the requirements of biological applications. Fig. 3E shows that surface modification of UCNPs yielded a successful coating of silica around $\mathrm{NaYF}_{4}: \mathrm{Yb} / \mathrm{Er} / \mathrm{Gd}(20 / 2 / 3 \mathrm{~mol} \%)$ UCNPs. After being modified by the Stöber method, the $\mathrm{NaYF}_{4}: \mathrm{Yb} / \mathrm{Er} / \mathrm{Gd} \mathrm{UCNPs}$ once capped by a layer of hydrophobic oleic molecules displayed hydrophilic functional groups $\left(-\mathrm{NH}_{2}\right)$ on their surfaces. The resultant amino-functionalized $\mathrm{NaYF}_{4}: \mathrm{Yb} / \mathrm{Er} / \mathrm{Gd}$ UCNPs could be easily dispersed in water and used for biological detections.

The existence of $\mathrm{NaYF}_{4}$ is indicated by the peaks for $\mathrm{Na}, \mathrm{Y}$, and $\mathrm{F}$ as well as other peaks from the energy dispersive spectroscopy (EDS) analysis results shown in Fig. S1a of the supplementary material. Unlike Fig. S1a, the peaks of C, O, and Si can be seen in Fig. S1b. Silicon and oxygen peaks can be attributed to the silica shell, and the carbon signal can be assigned to the methylene in the hydrolysate of APTES. It confirms the formation of the $\mathrm{SiO}_{2}$ layer, which proves the successful amino modification through the typical Stöber method. 
To further confirm the surface modification of $\mathrm{NaYF}_{4}: \mathrm{Yb} / \mathrm{Er} / \mathrm{Gd}$ UCNPs, FT-IR analysis was carried out to characterize the UCNPs before and after modification (see Fig. S2 in supplementary material). Before surface modification, there was a layer of oleic acid that is confirmed by the two peaks at 2914 and $2849 \mathrm{~cm}^{-1}$, which are attributed to the asymmetric and symmetric stretching vibrations of the methylene group in the oleic acid, respectively. The peak at $1469 \mathrm{~cm}^{-1}$ is the characteristic peak of a $\mathrm{COO}^{-}$bond. The oleic acid's characteristic peaks disappeared after surface modification. The peak at $1097 \mathrm{~cm}^{-1}$ results from the symmetrical stretching vibration of the $\mathrm{Si}-\mathrm{O}$ bond, which confirms the existence of a layer of silica. The amine group can be proved by peaks at 3432 and $1637 \mathrm{~cm}^{-1}$ collectively. Besides, the two peaks at 2929 and $2857 \mathrm{~cm}^{-1}$ are attributed to the substance of the APTES. The FT-IR and EDS analysis results show that the surface of the NaY- $\mathrm{F}_{4}: \mathrm{Yb} /$ Er/Gd UCNPs has been successfully amino functionalized.

\section{Pretreatment of R-PE}

The R-PE contained amino materials that would have affected the energy transfer between amino-modified $\mathrm{NaYF}_{4}: \mathrm{Yb} / \mathrm{Er} / \mathrm{Gd} \mathrm{UCNPs}$ and R-PE. Therefore, R-PE should be pretreated to remove ammonium salt prior to use. Here, we used a dialysis bag to remove the ammonium salt from R-PE. It can be seen that the baseline of the UV-Vis absorption spectrum of R-PE exceeds zero by more than $0.2 \mathrm{~cm}^{-1}$, whereas it tends to be zero after pretreatment (see Fig. S3 in supplementary material). This indicates that the ammonium salt was eliminated completely.

\section{Conjugation of $\mathrm{NaYF}_{4}: \mathrm{Yb}, \mathrm{Er}, \mathrm{Gd}$ UCNPs and R-PE}

There are two prerequisites for FRET; one is that the UV-Vis absorption spectrum of the acceptor overlaps well with the UC luminescent emission spectrum of the donor, and the other is that the donor and acceptor are in proximity to each other. Luminescence of RE ions caused by the $\mathrm{f}-\mathrm{f}$ transition [32] does not belong to the fluorescence category. So, the energy transfer that occurred in our system has been referred to as LRET instead of FRET in the field of RE luminescent materials.

It is known that R-PE can emit strong fluorescence and has a good absorption performance. Moreover, R-PE contains multiple carboxyl groups, making it possible to conjugate R-PE to amino-modified $\mathrm{NaYF}_{4}: \mathrm{Yb} / \mathrm{Er} / \mathrm{Gd}$ UCNPs. It can be seen from spectrum a in Fig. 4 that the pretreated P-RE shows a strong absorption band around $550 \mathrm{~nm}$ that can be used as an acceptor in LRET-based assays. Spectrum $b$ in Fig. 4 shows the luminescence spectrum of $\mathrm{NaYF}_{4}: \mathrm{Yb} / \mathrm{Er} / \mathrm{Gd} \mathrm{UCNPs}$, which have a strong emission bands at $543 \mathrm{~nm}$. The green emission of the UCNPs is suitable for use as an energy donor in the LRET-based assays. From Fig. 4, we can see that the UV-Vis absorption spectrum of R-PE overlaps with the luminescence spectrum of $\mathrm{NaYF}_{4}: \mathrm{Yb} / \mathrm{Er} / \mathrm{Gd} \mathrm{UCNPs}$ very well, and, thus, fulfills the first requirement of the LRET.

It can be seen from Fig. 5 that the luminescence intensity of the $\mathrm{NaYF}_{4}: \mathrm{Yb} / \mathrm{Er} / \mathrm{Gd} \mathrm{UCNPs}$ decreased obviously after R-PE was added and decreased still further after EDC was added to the system. From these data, it can be determined that the electrostatic attractions between nanoparticles and R-PE aid in shortening the distance between donor and acceptor. Furthermore, the addition of EDC to the system enables chemical conjugation between the donor and acceptor, further shortening the distance between them. As a result, the second requirement for energy transfer to occur is satisfied. The preconditions shown in both Figs. 4 and 5 indicate that the system can be used for energy transfer successfully.

After R-PE of different volumes, ranging from 0.002 to $0.13 \mathrm{ml}(0.875-56.9 \mu \mathrm{g} / \mathrm{ml})$, was added to the system, the green emission $(543 \mathrm{~nm})$ of UCNPs was obviously quenched. In the 
meantime, the luminescence of R-PE was enhanced somewhat, whereas the red emission $(659 \mathrm{~nm})$ of UCNPs was almost unchanged, as shown in Fig. 6A, because the UV-Vis absorption spectrum of R-PE does not overlap with the luminescence spectrum of $\mathrm{NaYF}_{4}: \mathrm{Yb} / \mathrm{Er} / \mathrm{Gd} \mathrm{UCNPs}$ at $659 \mathrm{~nm}$. It can be seen from Fig. 6A that the luminescence intensity of the $\mathrm{NaYF}_{4}$ UCNPs at $543 \mathrm{~nm}$ gradually decreases and the luminescence intensity of R-PE at $575 \mathrm{~nm}$ increases little by little with the increase of the R-PE concentration. We can see that the extent to which the luminescence intensity decreases at $543 \mathrm{~nm}$ is much greater than the extent to which it increases at $575 \mathrm{~nm}$.

Two linear relationships were developed in the system. One of them is between the Napierian logarithm of the UCNPs' luminescence intensity at $543 \mathrm{~nm}\left(\ln I_{\mathrm{UC}}\right)$ and the concentration of R-PE $(C)$, whereas the other is between the Napierian logarithm of the RPE's luminescence intensity $(\ln I)$ and the Napierian logarithm of the R-PE's concentration (ln $C$ ). In Fig. 6B, a good linear relationship can be established between $\ln I_{\mathrm{UC}}$ and the concentration of R-PE in the range of 0.875 to $56.9 \mu \mathrm{g} / \mathrm{ml}$ that follows the equation $\ln I_{\mathrm{UC}}=$ $5.947-0.016 C$, with a square of the related coefficient of 0.9992. In Fig. 6C, there is a good linear relationship between the Napierian logarithm of the R-PE's luminescence intensity and $\ln C$ in the R-PE concentration range of 0.875 to $56.9 \mu \mathrm{g} / \mathrm{ml}$. This relationship can be fitted by the equation of $\ln I=1.499+0.442 \ln C$, with a square of the related coefficient of 0.9991 . The R-PE DL of $0.5 \mu \mathrm{g} / \mathrm{ml}$ was obtained from the data in Fig. 6B, and the RSD of the detection is $2.0 \%(21.9 \mu \mathrm{g} / \mathrm{ml}, n=11)$. These results demonstrate the successful energy transfer between amino-modified $\mathrm{NaYF}_{4}: \mathrm{Yb} / \mathrm{Er} / \mathrm{Gd} \mathrm{UCNPs}$ and P-RE, which can be exploited for sensitive protein detection. When the concentration of R-PE exceeded $56.9 \mu \mathrm{g} /$ $\mathrm{ml}$, the luminescence signal no longer increased because the amount of the donor (UCNPs) was depleted and, thus, could not interact with the increasing acceptor (P-RE) concentration.

Here, the energy transfer between $\mathrm{NaYF}_{4}: \mathrm{Yb} / \mathrm{Er} / \mathrm{Gd}$ UCNPs and R-PE occurred when the amino groups on the surface of the NaY- $\mathrm{F}_{4}: \mathrm{Yb} / \mathrm{Er} / \mathrm{Gd} \mathrm{UCNPs}$ and the carboxyl groups of the R-PE interacted to bring them close enough. Surface modification of $\mathrm{NaYF}_{4} \mathrm{UCNPs}$ was completed by using a typical Stöber-based method, whereas there were multiple carboxyl groups of R-PE itself. The fact that amino-modified $\mathrm{NaYF}_{4}: \mathrm{Yb} / \mathrm{Er} / \mathrm{Gd} \mathrm{UCNPs}$ and R-PE can be conjugated without adding other materials can explain the existence of electrostatic attraction between $\mathrm{NaYF}_{4} / \mathrm{NH}_{2}$ and R-PE. In addition, they will be well conjugated under the activation of EDC, and the transfer efficiency was better. After energy transfer, the luminescence of the $\mathrm{NaYF}_{4}: \mathrm{Yb} / \mathrm{Er} / \mathrm{Gd} \mathrm{UCNPs}$ can be transferred to R-PE, so the luminescent spectrum of R-PE can be detected by NIR $(980 \mathrm{~nm})$ excitation. These results demonstrate that the LRET system consisting of amino-modified $\mathrm{NaYF}_{4}: \mathrm{Yb} / \mathrm{Er} / \mathrm{Gd}$ UCNPs and R-PE, which are brought closer to allow LRET to occur, can be used for sensitive protein detection.

This LRET system uses UCNPs instead of quantum dots (QDs) or organic dyes as an energy donor that can convert NIR light to visible light. The LRET system can be detected under NIR irradiation, so the UCNP-based LRET system is an ideal approach for biological detection. The detection of R-PE with such a low DL of $0.5 \mu \mathrm{g} / \mathrm{ml}$ has never been reported. The UCNP-based LRET system may also be used to detect other biomolecules such as peptides and target biomolecules [33,34].

\section{Conclusion}

After being doped with $\mathrm{Gd}^{3+}$ ions during preparation, phase transformation of $\mathrm{NaYF}_{4}$ UCNPs from cubic to hexagonal was greatly enhanced, so UCNPs with the same excellent UC properties were prepared with a shorter reaction time and lower reaction temperature. Our approach is more energy efficient and improves the reaction efficiency greatly. The 
synthesized $\mathrm{NaYF}_{4}: \mathrm{Yb} / \mathrm{Er} / \mathrm{Gd}$ UCNPs were amino modified and successfully used for the detection of R-PE through an LRET system, which was established with $\mathrm{NaYF}_{4}: \mathrm{Yb} / \mathrm{Er} / \mathrm{Gd}$ UCNPs as the donor and R-PE as the acceptor. Experimental results suggest that the LRET system is simple and effective for the detection of the technologically important protein RPE. Our method can find potential applications in the detection of other biological molecules due to its higher sensitivity.

\section{Supplementary Material}

Refer to Web version on PubMed Central for supplementary material.

\section{Acknowledgments}

We are grateful for support from the National Natural Science Foundation of China (20875011) and support from Northeastern University on PhD students. C.M. is thankful for financial support from the U.S. National Science Foundation (DMR-0847758, CBET-0854414, and CBET-0854465), National Institutes of Health (R21EB009909-01A1, R03AR056848-01, and R01HL092526-01A2), and Oklahoma Center for the Advancement of Science and Technology (HR11-006).

\section{References}

1. Auzel F. Upconversion and anti-Stokes processes with $f$ and $d$ ions in solids. Chem Rev. 2004; 104:139-173. [PubMed: 14719973]

2. Liang LF, Wu H, Hu HL, Wu MM, Su Q. Enhanced blue and green upconversion in hydrothermally synthesized hexagonal $\mathrm{NaY}_{1-X} \mathrm{Yb}_{X} \mathrm{~F}_{4}: \mathrm{Ln}^{3+}\left(\mathrm{Ln}^{3+}=\mathrm{Er}^{3+}\right.$ or $\left.\mathrm{Tm}^{3+}\right)$. J Alloys Compounds. 2004; 368:94-100.

3. Scheps R. Upconversion laser processes. Prog Quantum Electron. 1996; 20:271-358.

4. Yi G, Lu HS, Zhao YG, Yang W, Chen D, Guo L. Synthesis, characterization, and biological application of size-controlled nanocrystalline $\mathrm{NaYF}_{4}: \mathrm{Yb}, \mathrm{Er}$ infrared-to-visible up-conversion phosphors. Nano Lett. 2004; 4:2191-2196.

5. Lim SR, Riehn W, Ryu N, Khanarian C, Tung DT, Austin R. In vivo and scanning electron microscopy imaging of upconverting nanophosphors in Caenorhabditis elegans. Nano Lett. 2006; 6:169-174. [PubMed: 16464029]

6. Phillips MLF, Hehlen MP, Nguyen K. Upconversion phosphors: recent advances and new applications. Phys Chem Luminesc Mater. 2000; 99:123-129.

7. Downing E, Hesselink L, Ralston J, Macfarlane R. A three-color, solid-state, three-dimensional display. Science. 1996; 273:1185-1189.

8. Joubert MF. Photon avalanche upconversion in rare earth laser materials. Opt Mater. 1999; 11:181203.

9. Shalav A, Richards BS, Trupke K, Gudel H. Application of NaYF4:Er3+ up-converting phosphors for enhanced near-infrared silicon solar cell response. Appl Phys Lett. 2005; 8610.1063/1.1844592

10. Wang LY, Yan RX, Huo ZY, Wang L, Zeng JH, Bao J, Wang X, Peng Q, Li YD. Fluorescence resonant energy transfer biosensor based on upconversion luminescent nanoparticles. Angew Chem Intl Ed. 2005; 44:6054-6057.

11. Zhang P, Rogelj S, Nguyen K, Wheeler D. Design of a highly sensitive and specific nucleotide sensor based on photon upconverting particles. J Am Chem Soc. 2006; 128:12410-12411. [PubMed: 16984179]

12. Chen ZG, Chen HL, Hu H, Yu MX, Li FY, Zhang Q, Zhou ZG, Yi T, Huang CH. Versatile synthesis strategy for carboxylic acid-functionalized upconverting nanophosphors as biological labels. J Am Chem Soc. 2008; 130:3023-3029. [PubMed: 18278910]

13. Wei Y, Lu FQ, Zhang XR, Chen DP. Polyol-mediated synthesis and luminescence of lanthanidedoped $\mathrm{NaYF}_{4}$ nanocrystal upconversion phosphors. J Alloys Compounds. 2008; 455:376-384.

14. Wang M, Mi CC, Wang WX, Liu CH, Wu YF, Xu ZR, Mao CB, Xu SK. Immunolabeling and NIR-excited fluorescent imaging of HeLa cells by using $\mathrm{NaYF}_{4}: \mathrm{Yb}$, Er upconversion nanoparticles. ACS Nano. 2009; 3:1580-1586. [PubMed: 19476317] 
15. Wang M, Abbineni G, Clevenger A. Nanomed Nanotechnol Biol Med. 2011; 7:710-729.

16. Mai HX, Zhang YW, Sun LD, Yan CH. Size- and phase-controlled synthesis of monodisperse $\mathrm{NaYF}_{4}: \mathrm{Yb}$,Er nanocrystals from a unique delayed nucleation pathway monitored with upconversion spectroscopy. J Phys Chem C. 2007; 111:13730-13739.

17. Zhang YW, Sun X, Si R, You LP, Yan CH. Single-crystalline and monodisperse $\mathrm{LaF}_{3}$ triangular nanoplates from a single-source precursor. J Am Chem Soc. 2005; 127:3260-3261. [PubMed: 15755126]

18. Sun YJ, Chen Y, Tian LJ, Yu Y, Kong XG, Zhao JW, Zhang H. Controlled synthesis and morphology dependent upconversion luminescence of $\mathrm{NaYF}_{4}: \mathrm{Yb}, \mathrm{Er}$ nanocrystals. Nanotechnology. 2007; 1810.1088/0957-4484/18/27/275609

19. Chen JY, Herricks T, Xia YN. Polyol synthesis of platinum nanostructures: control of morphology through the manipulation of reduction kinetics. Angew Chem Intl Ed. 2005; 44:2589-2592.

20. Feldmann C, Jungk HO. Polyol-mediated preparation of nanoscale oxide particles. Angew Chem Intl Ed. 2001; 40:359-362.

21. Wang M, Mi CC, Zhang YX, Liu JL, Li F, Mao CB, Xu SK. NIR-responsive silica-coated $\mathrm{NaYbF}_{4}: \mathrm{Er} / \mathrm{Tm} / \mathrm{Ho}$ upconversion fluorescent nanoparticles with tunable emission colors and their applications in immunolabeling and fluorescent imaging of cancer cells. J Phys Chem C. 2009; 113:19021-19027.

22. Suyver JF. Novel materials doped with trivalent lanthanides and transition metal ions showing near-infrared to visible photon upconversion. Opt Mater. 2005; 27:1111-1130.

23. Heer S, Kompe K, Gudel HU, Haase M. Highly efficient multicolour upconversion emission in transparent colloids of lanthanide-doped $\mathrm{NaYF}_{4}$ nanocrystals. Adv Mater. 2004; 16:2102-2105.

24. Wang F, Chatterjee DK, Li ZQ, Zhang Y, Fan XP, Wang MQ. Synthesis of polyethylenimine/ $\mathrm{NaYF}_{4}$ nanoparticles with upconversion fluorescence. Nanotechnology. 2006; 17:5786-5791.

25. Jalil RA, Zhang Y. Biocompatibility of silica coated $\mathrm{NaYF}_{4}$ upconversion fluorescent nanocrystals. Biomaterials. 2009; 29:4122-4128. [PubMed: 18675453]

26. Li Q, Zhang Y. Monodisperse silica-coated polyvinylpyrrolidone/NaYF 4 nanocrystals with multicolor upconversion fluorescence emission. Angew Chem Intl Ed. 2006; 45:7732-7735.

27. Sepúlveda-Ugarte J, Brunet JE, Matamala AR, Martínez-Oyanedel J, Bunster M. Spectroscopic parameters of phycoerythrobilin and phycourobilin on phycoerythrin from Gracilaria chilensis. J Photochem Photobiol A. 2011; 219:211-216.

28. Sapsford KE, Berti L, Medintz IL. Materials for fluorescence resonance energy transfer analysis: Beyond traditional donor-acceptor combinations. Angew Chem Intl Ed. 2006; 45:4562-4588.

29. Wang M, Hou W, Mi CC, Wang WX, Xu ZR, Teng HH, Mao CB, Xu SK. Immunoassay of goat antihuman immunoglobulin $\mathrm{G}$ antibody based on luminescence resonance energy transfer between near-infrared responsive $\mathrm{NaYF}_{4}: \mathrm{Yb}$,Er upconversion fluorescent nanoparticles and gold nanoparticles. Anal Chem. 2009; 81:8783-8789. [PubMed: 19807113]

30. Wang F, Han Y, Lim CS, Lu YH, Wang J, Xu J, Chen HY, Zhang C, Hong MH, Liu G. Simultaneous phase and size control of upconversion nanocrystals through lanthanide doping. Nature. 2010; 463:1061-1065. [PubMed: 20182508]

31. Park YI, Kim JH, Lee KT, Jeon KS, Na HB, Yu JH, Kim HM, Lee N, Choi SH, Baik SI, Kim H, Park SP, Park BJ, Kim YW, Lee SH, Yoon SY, Song IC, Moon WK, Suh YD, Hyeon T. Nonblinking and nonbleaching upconverting nanoparticles as an optical imaging nanoprobe and T1 magnetic resonance imaging contrast agent. Adv Mater. 2009; 21:4467-4471.

32. Li CX, Lin J. Rare earth fluoride nano-/microcrystals: Synthesis, surface modification, and application. J Mater Chem. 2010; 20:6831-6847.

33. Cao B, Mao CB. Identification of microtubule-binding domains on microtubule-associated proteins by major coat phage display technique. Biomacromolecules. 2009; 10:555-564. [PubMed: 19186939]

34. Mao CB, Solis DJ, Reiss BD, Kottmann ST, Sweeney RY, Hayhurst A, Georgiou G, Iverson B, Belcher AM. Virus-based toolkit for the directed synthesis of magnetic and semiconducting nanowires. Science. 2004; 303:213-217. [PubMed: 14716009] 


\section{Appendix A. Supplementary data}

Supplementary data associated with this article can be found, in the online version, at doi: 10.1016/j.ab.2011.11.008. 

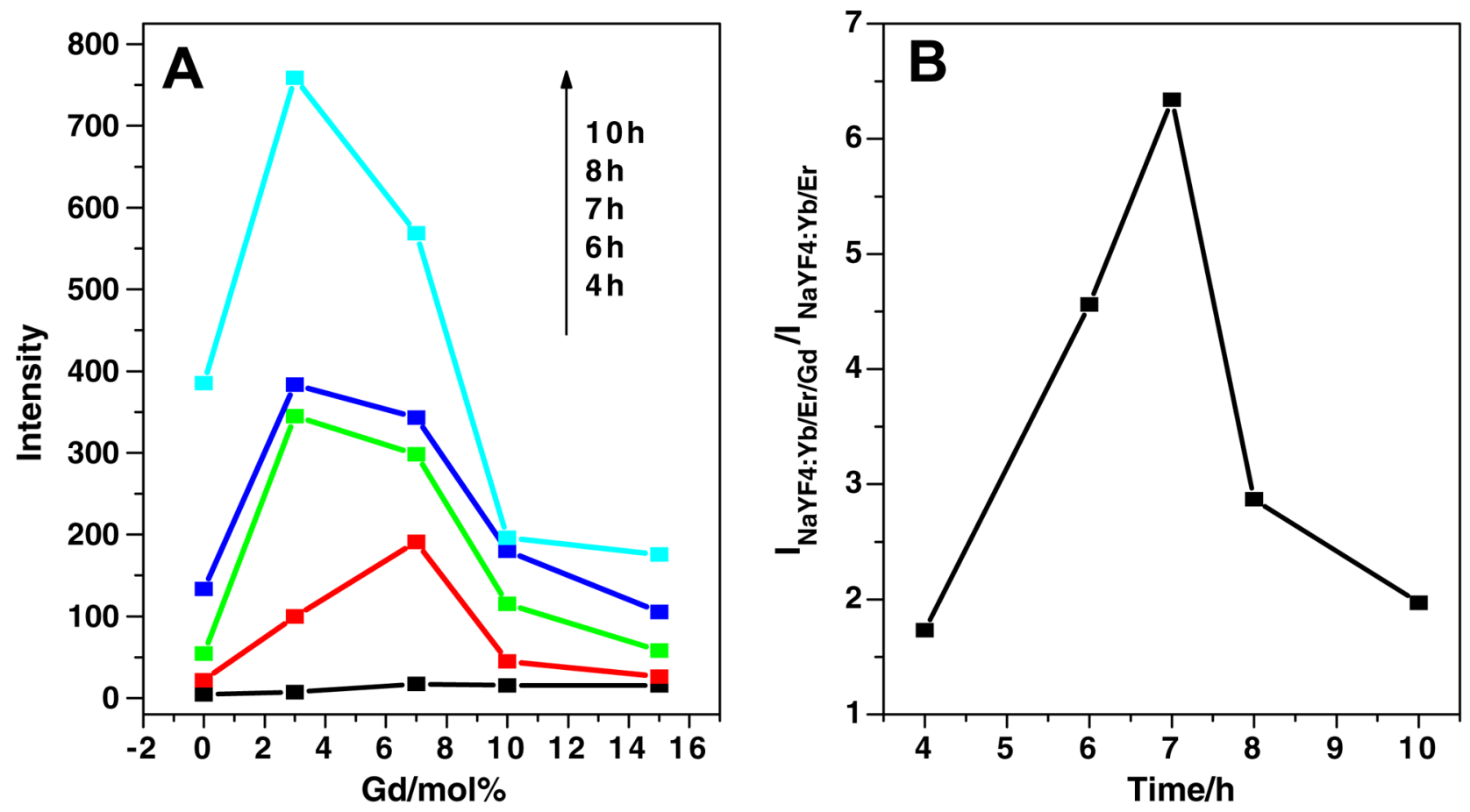

Fig. 1.

(A) Tendency chart of luminescence intensity of UCNPs at $543 \mathrm{~nm}$ (980 nm excitation, 0.42 watt) affected by both the reaction time and doped molar ratio $\mathrm{Gd}^{3+}$. (B) Tendency chart of luminescence enhancement from $\mathrm{NaYF}_{4}: \mathrm{Yb} / \mathrm{Er}(20 / 2 \mathrm{~mol} \%)$ to $\mathrm{NaYF}_{4}: \mathrm{Yb} / \mathrm{Er} / \mathrm{Gd}(20 / 2 / 3$ mol\%) affected by reaction time. 


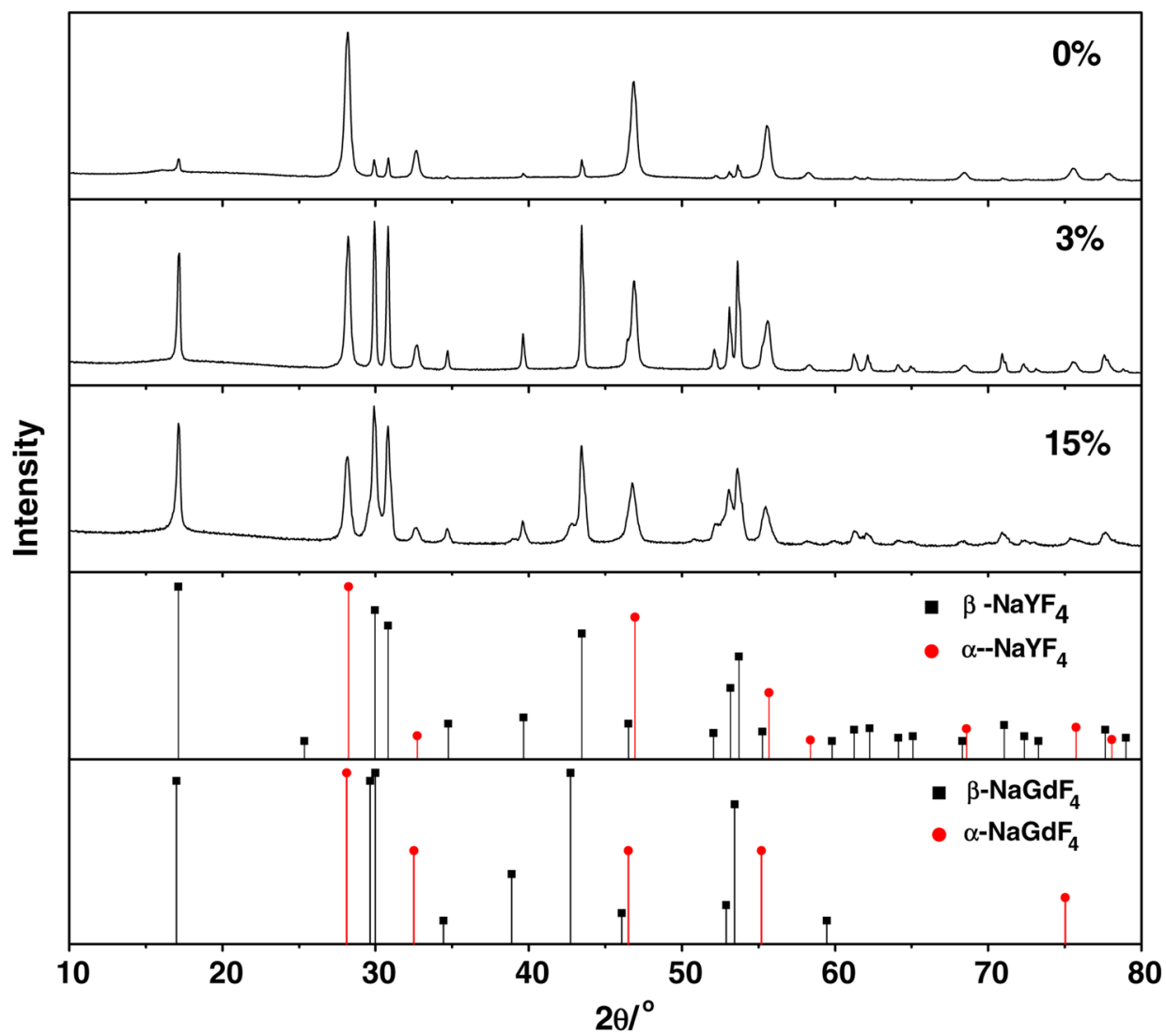

Fig. 2.

X-ray powder diffraction patterns of the $\mathrm{NaYF}_{4}: \mathrm{Yb} / \mathrm{Er} / \mathrm{Gd}_{X}(x=0,3$, and $15 \mathrm{~mol} \%)$ UCNPs. 

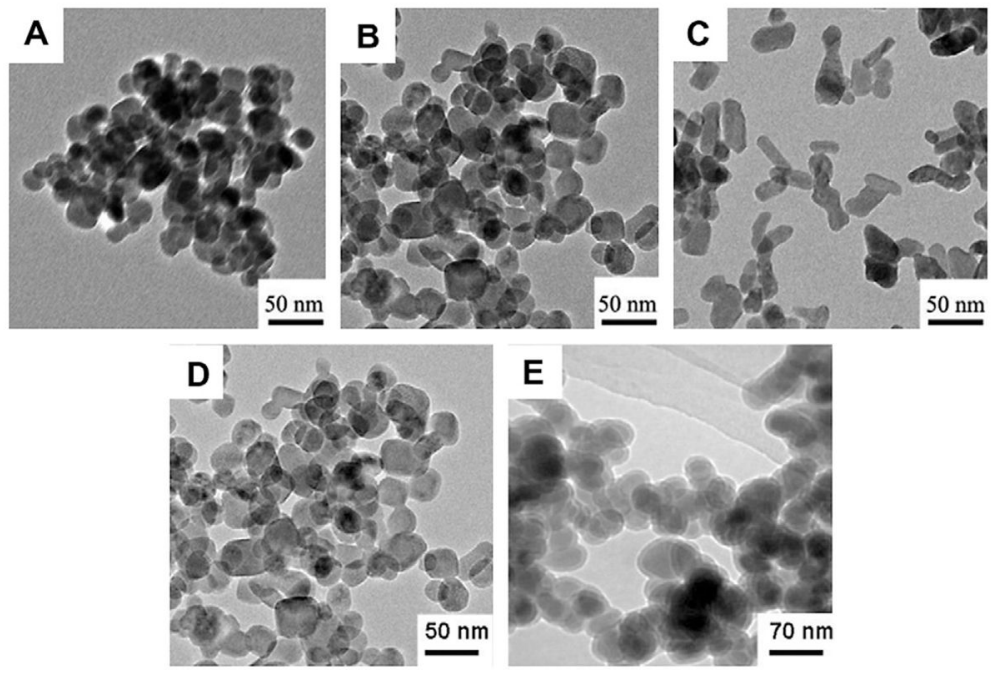

Fig. 3.

(A-C) TEMs of the $\mathrm{NaYF}_{4}: \mathrm{Yb} / \mathrm{Er} / \mathrm{Gd}_{X}$ doped with different concentrations of $\mathrm{Gd}^{3+}:(\mathrm{A}) x=$ $0 \mathrm{~mol} \%$; (B) $x=3 \mathrm{~mol} \%$; (C) $x=15 \mathrm{~mol} \%$. (D,E) TEMs of UCNPs before (D) and after (E) surface modification. 


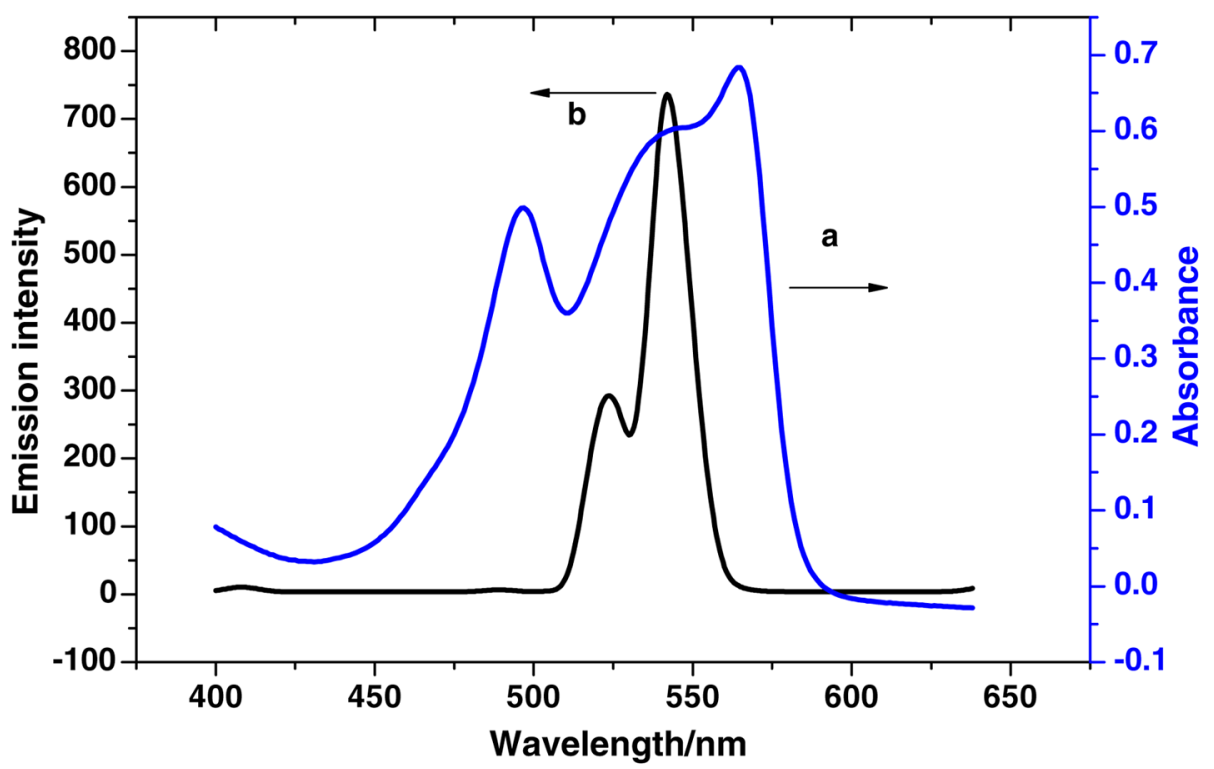

Fig. 4.

UV-Vis absorption spectrum of R-PE (a) and emission spectrum of $\mathrm{NaYF}_{4}: \mathrm{Yb} / \mathrm{Er} / \mathrm{Gd}$ UCNPs (b). 


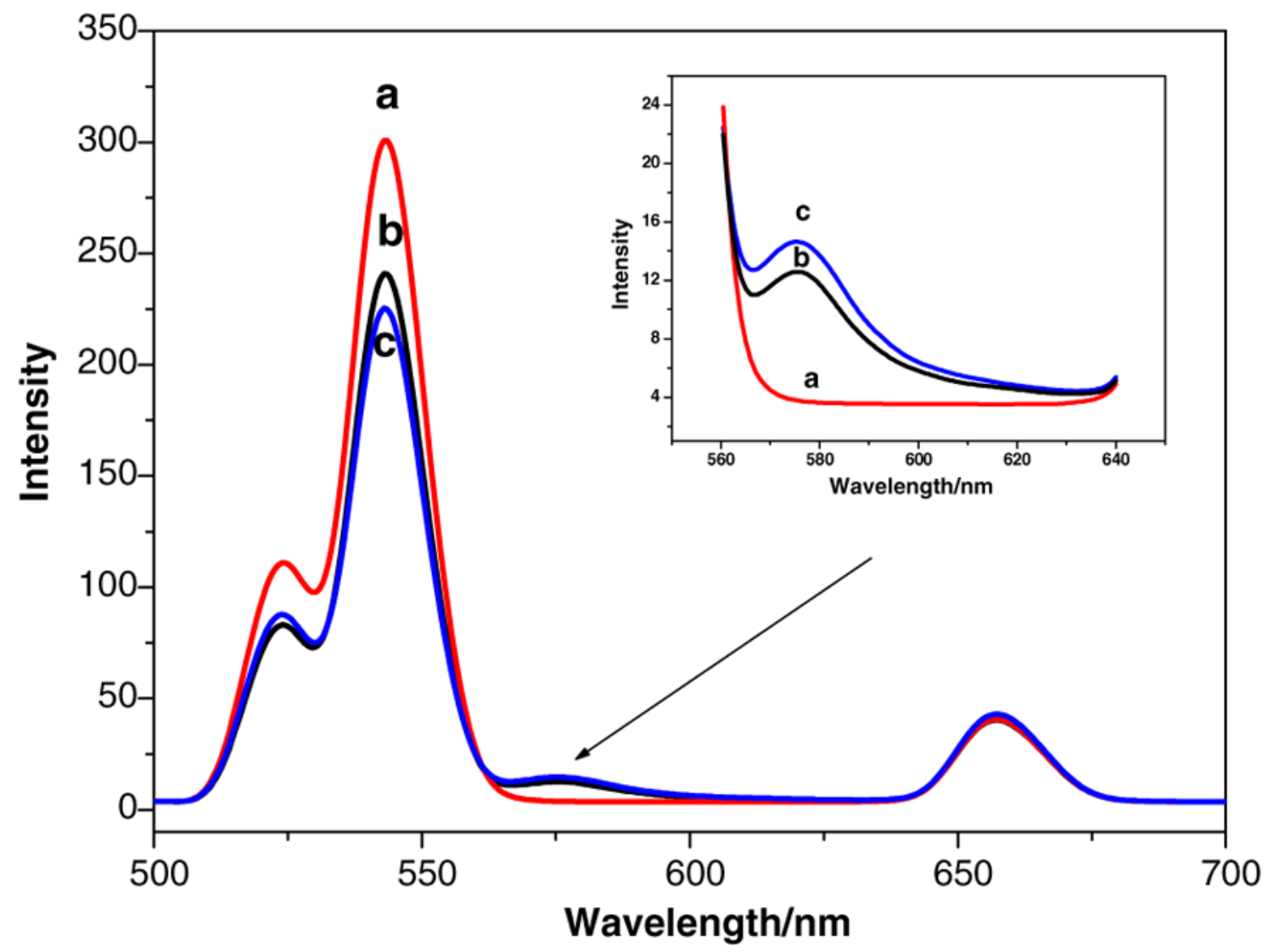

Fig. 5.

Emission spectra of UCNPs (a), UCNPs + R-PE (b), and UCNPs + R-PE + EDC (c). 

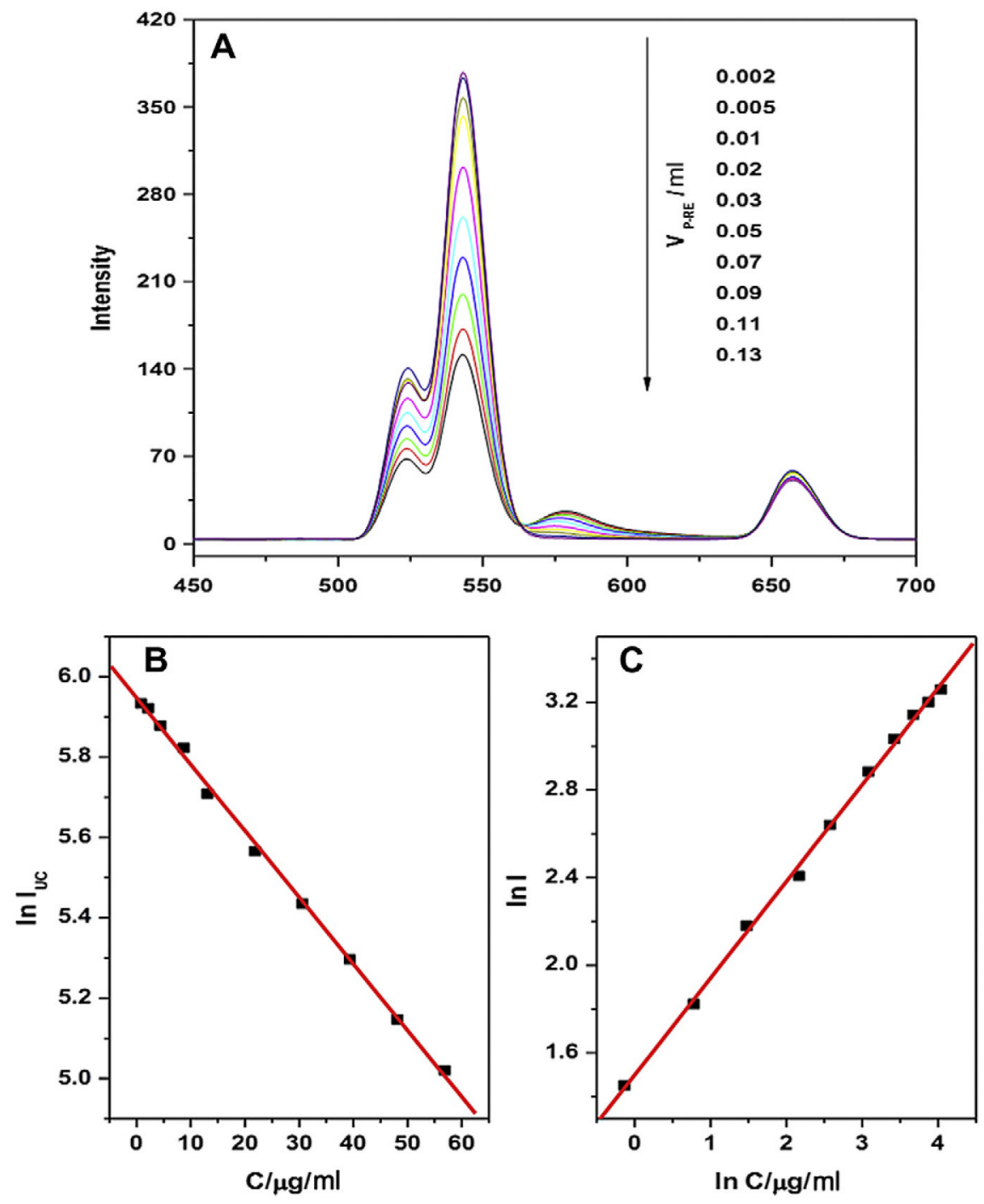

Fig. 6.

(A) Luminescence spectra of UCNPs at different volumes of R-PE. (B) Linear relationship between the Napierian logarithm of the UCNPs' fluorescent intensity at $543 \mathrm{~nm}$ and the concentration of R-PE. (C) Linear relationship between the Napierian logarithm of the RPE's fluorescent intensity and the Napierian logarithm of the R-PE's concentration. 